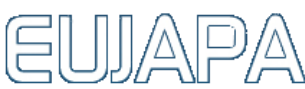

Article

\section{Elite Athletes' Perspectives about the Importance of Psychological Preparation and Personal Experiences with Sport Psychology}

Tânia Bastos ${ }^{1 *}$, Rui Corredeira ${ }^{2}$, Michel Probst ${ }^{3}$ and António M. Fonseca ${ }^{1}$

Received: 24 $4^{\text {th }}$ N ovember 2018; A ccepted: 30 Jh January 2020; Published: $18^{\text {th }}$ A pril 2020

\begin{abstract}
A bstract: Portuguese elite athletes with disabilities $(n=14)$ were interviewed to explore the importance assigned to psychological preparation and their personal experiences on sport psychology. Semi-structured interviews were conducted using standard qualitative methodology. All the participants highlighted the importance of psychological preparation in sports performance. M oreover, it was evident a gap on applied sport psychology among the athletes. M ost of the athletes never had any kind of psychological intervention for sport. Although some participants mentioned barriers to sport psychology intervention (e.g., athlete's age, perception of psychological skills as innate characteristics, and the opinion of others), most of the athletes expressed receptiveness to engage in psychological skills training and stressed the need for that support. Some recommendations for future sport psychology interventions are presented as well as the study limitations.
\end{abstract}

Keywords: psychological skills; sport psychologists; qualitative methodology; disability

\section{Introduction}

One of the major challenges in applied sport psychology in relation to disability sport is the development of psychological skills training programs. In the last decades, several studies have been conducted to show the pertinence and applicability of psychological skills and strategies in athletes with different disabilities (Blumenstein \& Orbach, 2015; de Bressy de Guast, Golby, Van Wersch \& d' A rripe-Longueville, 2013; Hanrahan, 2007; M artin, 2017). However, missing issues in the study of psychology preparation includes how athletes with disabilities perceive the importance of psychological skills; and another is their receptiveness to sport psychology intervention. This research gap was emphasized by Page, M artin, and Wayda (2001), who studied the attitudes of wheelchair basketball players toward seeking sport psychologists.

Although Hanrahan (2015) considered that athletes with disabilities appreciate and are receptive to sport psychology services and to psychological skills training programs when they are available, research showed that athletes with disabilities also expressed equivocal positions towards sport psychology interventions. For instance, during the social validation process of an imagery intervention program for wheelchair basketball players, Shearer, M ellalieu, Shearer, and RoderiqueD avies (2009) found that most of the athletes were satisfied with the program and considered it useful, but some athletes also expressed less positive opinions. Similarly, in the study of Page and colleagues (2001), wheelchair basketball players revealed receptiveness towards meeting with a sport psychologist and acknowledged the need for a sport psychologist intervention. N evertheless, a variety of stigmas related to seeing sport psychologists were identified by the previously mentioned authors.

Research on athletes without disabilities pointed out less positive and receptive perspectives toward sport psychologists' interventions. For example, Weinberg and Gould (2011) summarized a 
range of stigmas that may undermine the adherence to psychological skills training programs. The ideas that psychological skills training takes too much time from the practice schedule, that psychological skills are innate by nature, and that psychological skills training is associated with psychological or mental health problems are some of the most referred stigmas. Therefore, sport psychologists need to be aware of an athlete's readiness to use psychological skills to decide the best direction for intervention (Leffingwell, Durand-Bush, W urzberger, \& Cada, 2005). As such, the athletes' motivations, beliefs, and behaviors concerning sport psychology and psychological skills training programs must be analyzed in order to change mindsets and increase the number of athletes that adhere to sport psychology interventions (Bull, 1991).

Since the study of Page and colleagues (2001), the lack of knowledge about the attitudes of athletes with disabilities regarding the receptiveness to working with sport psychologists or the importance of psychological skills training still remains. In this context, another important issue is the insufficient number of opportunities that athletes with disabilities have to engage in systematic and formal psychological skills training (M artin, 2010). Even at the Paralympic level, not all the athletes have access to sport psychology services to support their preparation (Dieffenbach, Statler, \& M offet, 2010, M ay). The professionalization of disability sport has raised the awareness and increased the contact of sport psychologists in this population (Bawden, 2006), but it is necessary to understand if, in practice, that interest is accomplished. Consequently, the study of athletes' personal experiences with sport psychology seems to be relevant. Research studies have also shown that athletes who have had previous contact with sport psychologists tend to have more favorable views on these specialists than those who have never had contact with sport psychologists ( $D$ aw \& Burton, 1994).

However, the effectiveness of a sport psychology intervention does not rely solely on the athletes' attitudes and perceptions about the importance of psychological skills training. The sport psychologist consultant expertise, knowledge, experience and perceptions about disability sport may affect the working relationship (Schinke \& H anrahan, 2009). H anrahan (2015) argued that working with athletes with disabilities can be a rewarding experience and also an opportunity for professional development for these practitioners. Moreover, working in this population may improve the communication skills of the practitioner. Therefore, sport psychologists must prepare themselves, developing competences and acquiring specific knowledgeto establish successfully relationships with the athletes, coaches and other professionals.

In this sense, the primary focus when working with an athlete with a disability must be on the psychological skills development and performance enhancement and not on the disability. However, if the athlete approaches his/her disability in a session, then the sport psychologist must be comfortable and prepared to clarify that issue (H anrahan, 2015). M oreover, to understand the needs and goals of athletes with disabilities, the sport psychologists must be aware of the specific challenges that may affect this group of athletes (e.g., accessibility needs; reliance on equipment, other people and medication; classification; body pains; travel arrangement) (M artin, 2005).

Finally, the sport psychologists must critical analyze their own beliefs about disability to identify potential myths and stereotypes. It is crucial to overcome limiting or erroneous preconceptions they hold about the athletes' abilities. Overall, the sport psychologists have to be open-minded and flexible to adapt their psychological training to the specific needs of each athlete (Bastos and M artin, 2015). Therefore, the aim of the present study was to investigate Portuguese elite athletes to determine the importance assigned to psychological preparation in sport performance. Additionally, the athletes' personal experiences with sport psychology were analyzed. 


\section{Materials and Methods}

\section{Participants}

The sample (Table 1) was composed of fourteen athletes (twelve males and two females) with visual impairment $(n=5)$ and physical disability $(n=9)$. With regard to the disability onset, eight athletes had congenital and six acquired disability. The participants' ages ranged from 17 to 40 years ( $M=29.4 y r s ; S D=6.5 y r s)$. A purposive sampling was selected based upon two criteria: i) elite status (i.e., all athletes were included in the Portuguese Paralympic Project), and ii) sport representativeness (i.e., the sample represented the Paralympic sports more prevalent in the Portuguese team, namely boccia $n=3$, swimming $n=5$, track and field $n=5$, and rowing $n=1$ ). According to Smith (2018), small samples purposefully chosen offer deep and rich knowledge that should be seen as unique strengths of qualitative research. All the athletes had international experience and most $(n=13)$ had earned medals in Paralympic games or W orld and European championships. In Table 1 detailed information about the sample characteristics is provided. This research was approved by the Faculty's ethical commission. A thletes gave their informed consent to participate in the study.

\section{Instrument}

Data was collected from a semi-structured and open-ended interview focused on the athletes' perspectives regarding their psychological preparation and their personal experiences with sport psychology. The use of semi-structured interview allows a co-construction of knowledge due to the unique interactions between the participants and the interviewer. M oreover, the use of open-ended questions facilitates both interviewer and interviewee roles allowing a flexible and responsive discussion (Smith \& Sparkes, 2016).

Initially, introductory comments about the purpose of the research and information about the structure of the interview were presented to the participants. The athletes were also informed that a copy of the interview would be sent to them for a validity check. It was emphasized that the focus was on the athlete's own experiences and perspectives, and there were no right or wrong answers. Some brief key definitions (e.g., of "sport psychology", "psychological preparation", and "psychological skills") were discussed with the participants. The main goal was to establish rapport and to orient athletes to the interview process. The main portion of the interview focused on central themes of the study, questioning the athletes about the importance given to psychological preparation (e.g., What is your opinion about the influence of psychological preparation in sport performance?) and about experiences in the field of sport psychology (e.g., Have you ever worked with a sport psychologist? A re you receptive to work with a sport psychologist? D o you have any psychological weaknesses that you would like to improve?). Finally, participants wereinvited to complete or add information to their responses to the interview questions or to other conversation topics that they considered relevant to thepurposes of the investigation. A thletes wereal so asked to reflect on theinterview styleand content.

The structure of the interview guide was based on Bastos, Corredeira, Probst and Fonseca (2014) methodology and the interview protocol was adapted to the perspectives of athletes with disability. An initial piloting exercise, with a male wheelchair basketball player (aged 28, with spinal cord injury, and ten years of international sport experience) was used to refine the interview guide.

\section{Procedures}

The participants were individually interviewed, face-to-face by the first author. The data were captured in a one-time event lasting approximately 40 minutes. The interviews were audio taped and transcribed verbatim using an unfocused approach. The transcribed interviews were sent to each participant. Participants were encouraged to generate additional data and give their insights. Reflections offered by participants helped to create a meticulous and rich dialogue between interviewer and interviewee (Smith \& M cGannon, 2018). 
Table 1. Summary of sample characteristics

\begin{tabular}{cccc} 
Athletes & Disability & \# International & Best Results \\
& Classification & Competitions / year & \\
\hline
\end{tabular}

\begin{tabular}{|c|c|c|c|}
\hline \multicolumn{4}{|c|}{ Track and Field } \\
\hline Richard & Physical disability - T54 & 8 & Bronze medal World championship. \\
\hline John & Visual impairment - TF12 & 2 & Bronze medal European championship; participation in Paralympic Games. \\
\hline James & Visual impairment - TF12 & 2 & $\begin{array}{l}\text { Gold medal in Paralympic Games and Paralympic record; gold medal in two World championships and } \\
\text { two world records. }\end{array}$ \\
\hline Martin & Visual impairment - TF12 & 2 & $\begin{array}{l}\text { Silver and bronze medal in two Paralympic Games; gold and silver medal in two World championships; } \\
\text { bronze medal in two European championships. }\end{array}$ \\
\hline Michel & Visual impairment - T11 & 2 & Bronze and silver medal in two European championships; participation in Paralympic Games. \\
\hline \multicolumn{4}{|l|}{ Boccia } \\
\hline Peter & Cerebral palsy - BC3 & 2 & Multiple times Paralympic champion; multiple times World, World Cup, and European champion. \\
\hline William & Cerebral palsy - BC3 & 2 & Gold medal in two Paralympic Games; multiple times World, World Cup, and European champion. \\
\hline Arthur & Cerebral palsy - BC1 & 2 & Gold and silver medal in two Paralympic Games; silver medal in World championship. \\
\hline \multicolumn{4}{|l|}{ Swimming } \\
\hline Benjamin & Physical disability - S9 & 2 & Silver and bronze medal in European championship; participation in Paralympic Games. \\
\hline Andrew & Physical disability - S10 & 2 & Silver and bronze medal in two European championships. \\
\hline David & Physical disability - S10 & 3 & Participation in World and European championships. \\
\hline Christophe & Physical disability - S3 & 3 & Participation in international meeting. \\
\hline Vincent & Physical disability - S4 & 4 & Bronze medal in three European championships; participation in Paralympic Games. \\
\hline Rose & Physical disability - S5 & 2 & Multiple times medaled in World and European championships; participation in Paralympic Games. \\
\hline \multicolumn{4}{|l|}{ Rowing } \\
\hline Anne & Physical disability - ASW1x & 3 & Bronze medal in World championship; participation in Paralympic Games. \\
\hline
\end{tabular}




\section{D ata Analysis}

An interpretive phenomenological analysis aiming to explore in detail participants' personal lived experience was adopted in the present study. Specifically, inductive techniques were privileged to allow unanticipated topics or themes to emerge during analysis. In practice, the research process involved an interplay between induction and deduction (Smith, 2004). Participants' perspectives on the importance of psychological preparation and their personal experiences with sport psychology were analyzed using thematic analysis (Braun, Clark, \& W eate, 2016). Different steps were followed to identify the major themes of this research. First, the main researcher carefully read and reread the interview transcripts to become completely familiar with the content of each interview, then summarized the key points outlined by the participants (i.e., immersion phase). N ext, a list of different codes were identified according to the statements of the participants in each area of the interview (i.e., initial codes phase). N ext, the different codes were organized into themes. The goal of this phase was the inductive identification of emergent themes based on the organization of the codes into meaningful themes. Consequently, themes were named and defined. Finally, the different themes were organized in overarching themes (i.e., themes that capture more than one specific idea). The researcher had to refine and define the themes to ensure that were unique and captured the data essence. To provide an ultimately validity check, the main researcher reread all the transcripts and verified that all codes and themes formed a coherent pattern within and across the dataset (Braun, Clark, \& W eate, 2016). Segments of the text (i.e., verbatim quotes from participants) were provided by the researcher. A frequency analysis was also conducted to represent the number of citations of each code and the number of athletes who mentioned the themes.

\section{Critical Friends}

To ensure quality and validity of the research, the main researcher used the help of a "critical friend" (i.e., another author) to discuss the data. According to Smith and McGannon (2018), "critical friends" is described as a critical dialogue between people that encourages reflection and critical feedback. It is expected that multiple explanations and interpretations of the data emerged during this process.

\section{Results}

The thematic analysis exposed two general dimensions that emerged from 45 raw data themes mentioned by the elite athletes. The dimensions were abstracted from 6 second-order subthemes and these from 13 first-order subthemes represented in Figures 1 and 2. Representative quotations from the transcripts are interspersed amid the results to clarify the emergent themes.

\section{The relation between psychological factors and sport performance}

This dimension puts in evidence the athletes' perspectives about psychological factors interference on their sport performance. Nineteen raw data themes comprised this dimension and three second-order subthemes were used to define it (Figure 1).

The athletes were unanimous in stating that psychological preparation is important for sport performance. Several participants explained their view of psychological preparation using the multifactor approach of performance. Psychological preparation emerged as one factor, among others (e.g., physical, technical, tactical, nutritional) that interfere in an athlete's performance. For example, Andrew's explained, "To be a good athlete, it's like a puzzle. There are several important pieces training, resting, and nutrition - and that [psychological preparation] is one more important piece of the puzzle". 


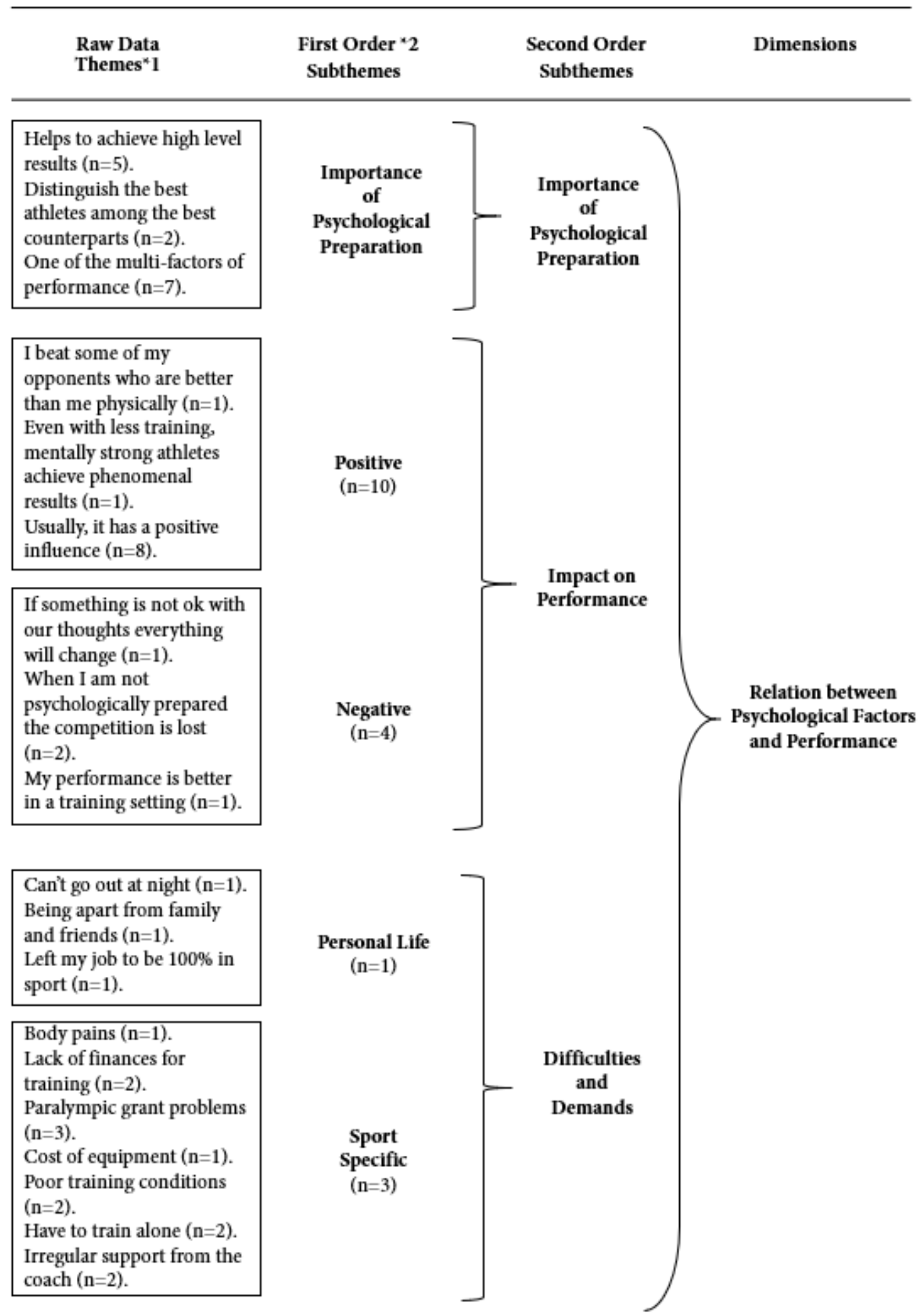

Figure 1. The relation between psychological factors and sport performance. N ote: *1 The number following each raw data theme indicates the number of times that it was reported; *2 The number below the first order subthemes indicates the number of athletes who reported them.

M ost of the athletes considered that, globally, psychological preparation has a positive impact on their performance. However, some participants mentioned that psychological preparation can havea negative impact, decreasing the expected outcomes. James mentioned "In training settings I can achieve a higher performance than in competition because the psychological factor, it's not so big. It's difficult for me to show my true value". In addition, Benjamin noted "I have examples of 
competitions where I was very well physically, but psychologically I was a disgrace and the competition ended badly".

The last second-order subtheme, difficulties and demands, enumerated demanding situations that athletes have to face at the elite level (i.e., personal life and sport-specific difficulties). Problems with the Paralympic grant were mentioned by some athletes. As explained by Rose "The Paralympic grant has a four months' delay and that is messing with the athletes' minds. ... It is an aspect that is already disturbing our psychological side". On the other hand, Richard argued "My grant doesn't allow me to quit my job. ... I would have more time to practice and, psychologically, that would benefit me a lot. But this is our reality ...".

\section{Athletes' personal experience with sport psychology}

Twenty-six raw data themes were included in this dimension (Figure 2). Personal experience is related with a group of contacts with sport psychology that athletes had during their sports careers. The dimension comprised three second-order subthemes: previous contact with sport psychologists, receptiveness to working with sport psychologists, and psychological weaknesses.

Most of the athletes had never worked with sport psychologists and had not experienced any kind of psychological intervention related to sport. Peter and Arthur (boccia players) mentioned they had already had contact with a general psychologist who gave support to the athletes in their sport club. However, both players considered the contact unhelpful in the sport context as the psychologist was not an expert in sport psychology. Although some athletes referred to having had some previous contact with sport psychologists, they considered that it was not appropriate or either systematic. Vincent's described his experience "Once, on a national team stage, some sport psychologists appeared and did individual interviews. Then, we did some games to build team spirit and cohesion, but nothing more than that".

Receptiveness to working with sport psychologists is represented by three first-order subthemes: receptiveness, barriers concerning sport psychologists' intervention, and coach's task. The majority of the athletes in the present study showed receptiveness to this type of intervention and highlighted the need to give to all athletes on national and club teams access to it. The participants used the example of other countries (e.g., United Stated of America, Brazil) to show the importance of including sport psychologists on the technical staff. Additionally, they referred to the fact that Portugal was one of the few countries that did not have sport psychologists on the national teams. The need to educate the athletes about the importance of psychological training was mentioned by $M$ ichel. M ichel pointed out that sport federations should deliver athletes courses and books to provide detailed information about this topic. Although most of the participants were receptive to a sport psychology intervention, some athletes assumed other positions. Participants shared ideas that can be considered barriers to a sport psychology intervention. For example, John believed that he is too old to get benefits from a sport psychology intervention,

I am too old [ 36 years old] for that. ... That [sport psychologist intervention] should be a concern for the younger and talented athletes. ... It's important for them in order to be able to have a long international career, but not for me.

In addition, Vincent expressed serious doubts about the usefulness of this type of intervention. The following expression is quite representative of that,

I 100-percent believe that the psychological side of the athlete is extremely important; however, I can't see how a sport psychologist intervention can work out. ... My question is: An athlete has a certain problem in competition and in dialogue with the sport psychologist he/she is able to overcome it. If another problem appears, will the athlete be able to solve it alone or will he/she need to be constantly helped? On the other hand, the sports world is very small. If the other athletes know about this situation, to what extent can this become a weakness for the athlete? 


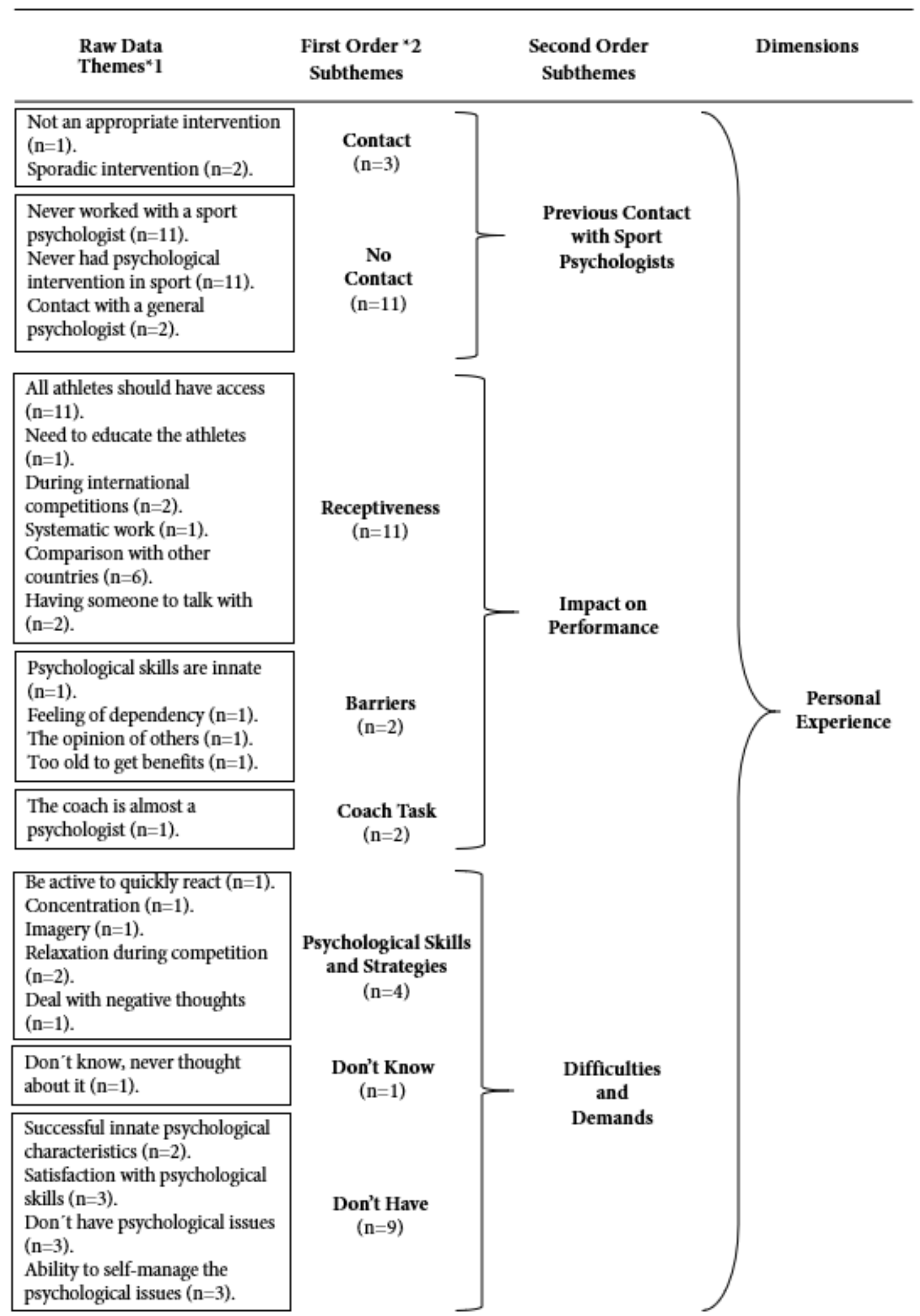

Figure 2. Athlete's personal experiences with sport psychology. N ote: *1 The number following each raw data theme indicates the number of times that it was reported; $* 2$ The number below the first order subthemes indicates the number of athletes who reported them.

Psychological weakness emerged from three first-order subthemes: psychological skills and strategies, do not know, and do not have. When asked specifically about aspects in individual psychological preparation that athletes would like to improve on, few participants mentioned 
psychological skills and strategies such as activation and relaxation in stressful moments. M artin did not know how to answer because he had never thought about the issue. M ost of the participants believed that they did not have psychological weaknesses.

\section{Discussion}

The purpose of this exploratory and descriptive study was to examine the importance that Portuguese elite athletes with disabilities assign to their psychological preparation. Additionally, it was intended to report the personal experiences of the athletes with sport psychology. In relation to the athletes' perspectives on psychological factors, the sample was unanimous in acknowledging psychological preparation as an important factor in sports performance. Similarly, $\mathrm{H}$ anrahan, Grove, and Lockwood (1990) noted that athletes with visual impairment participating in a psychological skills training program considered psychological factors responsible for $50 \%$ of their performance outcomes. One of the reasons highlighted by the present sample was that sport performance resulted from a combination of multi-factors, of which psychological preparation was one. Another explanation specifically pointed to the importance of psychological preparation at the elite level, were the demands of training/competition and the similarity of physical skills between athletes. In this regard, psychological preparation seems to be the "X factor" that will differentiate the best among the best. Factors that leads to winning a medal, beating a personal record, or being selected for a national team is often psychological in nature when similar levels of competition are taken into account (Martin, Malone, \& Hilyer, 2011). It is well known that more successful players consistently use psychological skills (e.g., concentration, determination, commitment, self-regulation of arousal) and strategies (e.g., goal setting, imagery, coping strategies, competitive plans) to prepare themselves to achieve maximal performance (W einberg $\&$ Gould, 2011). In disability sport context, M artin and $M$ alone (2013) showed that an increased used of mental skills was associated with better engagement in sport, with mental skills use explaining $50 \%$ of the variance in athlete engagement.

The "difficulties and demands" subtheme emerged from the statements of three athletes. Being engaged at the elite level represents a complete life commitment for athletes. W heeler and colleagues (1999) explained that athletes make a personal investment on their disability sport careers that, depending on the degree of commitment, may lead to the exclusion of other life aspects (e.g., family, relationships, career, and education). D ealing with physical pain was another factor mentioned by an athlete with a spinal cord injury (SCI). M artin and Wheeler (2011) explained that for athletes with disabilities (e.g., $\mathrm{SCI}$ ), body pain can interfere in sport, limiting physical activity. Financial problems were mentioned in relation to reduced values, or delays in payment, of the Paralympic grants. This lack of financial support often limits the conditions for training and competing, specifically when athletes have to support their own travel/training expenses or the maintenance of sport equipment that can be very expensive. The impact of financial problems also emerged in the study of Campbell and Jones (2002). The lack of financial support was identified as a stress factor when demands or costs of wheelchair basketball were addressed by elite male players.

On the other hand, poor training conditions associated with the lack of training partners and lack of continuous support from the coach were also mentioned in the present research. $M$ artin and Wheeler (2011) explained the importance of social support in training settings since many athletes with disabilities have to train by themselves. Likewise, Williams and Taylor (1994) pointed out feelings of isolation due to the lack of training partners as one of the reasons for dropping out among non-elite wheelchair athletes. Lack of proper coaching conditions was another disability sport consideration mentioned by Martin and Wheeler (2011) and shared by two athletes in the present study. M ost of the athletes with disabilities do not have appropriate coaching or simply do not have coaches ( $M$ artin \& W heeler, 2011). All these factors may interfere in the psychological preparation of the athletes, disturbing expected performance outcomes.

Although Gould, Flett, and Bean (2009) referred to a growing acceptance of applied sport psychology, with athletes being encouraged to mentally prepare to perform, this was not verified in 
the present study. M ost of the athletes interviewed had never had contact with sport psychologists or any kind of psychological intervention in sport, and those who mentioned $(n=3)$ did not classify it as suitable. This is a very concerning fact since it is well known that optimal mental preparation is achieved through a long-term and structured intervention tailored by experts in coaching and counseling (Samulski, N oce \& Costa, 2011). If it is expected that elite athletes achieve their maximal potential, all their skills have to be systematically developed and the role of the sport psychologist is crucial for that accomplishment.

Although most of the athletes of the present study had never had previous contact with sport psychologists, the expressed receptiveness to work with these specialists was quite considerable. The international competitive experiences allowed the athletes to gain critical insight on the topic. Several athletes used the example of successful competitive countries (e.g., the Brazilian case) to highlight the need to have sport psychologists support during major events. Therefore, the Paralympic Brazilian reality can be seen as an example of good practice of applied sport psychology that countries like Portugal should follow. Another expressed concern was the need to educate the athletes about the importance of psychological preparation and thetraining of psychological skills, providing sources of knowledge accessible to all athletes. Courses, workshops, and specific literature were some examples mentioned. As such, it puts forth the idea that investment in the education of athletes on the benefits of psychological training can be an important step in changing the Portuguese reality here presented.

The literature often describes a variety of myths and roadblocks that can negatively interfere in theadherence of athletes to sport psychology programs (Burton \& Raedeke, 2008; W einberg \& Gould, 2011). Three major barriers were mentioned in our study: i) the athlete's age, ii) the idea of psychological skills as innate skills, and iii) the opinion of others. O ne athlete considered himself too old to get benefits from a sport psychology intervention. Research emphasizes the importance of introducing psychological skills training programs in the beginning of athletes' sports careers to enhance personal growth and performance, allowing thefull achievement of theindividual's potential (Burton \& Raedake, 2008). However, it is common in disability sport for active and fit athletes to participate in elite competitions until a later age. Psychological intervention can benefit all the athletes, and psychological concerns cannot be neglected based on an athlete's age.

A nother athlete questioned the usefulness of a sport psychology intervention when the athlete is psychologically "weak." This perspective is in line with the stereotype that psychological skills are innate characteristics that cannot be taught, or an athlete is born with a psychological predisposition, or he/she is able to develop skills based on personal experiences (Burton \& Raedake, 2008). In this regard, it seems important to enlighten athletes about the nature of psychological skills. Psychological skills have to be taught and trained consistently to achieve automaticity in performance, just as physical skills are (Burton \& Raedake, 2008; W einberg \& Gould, 2011). It is important to note that the poor psychological training experienced by athletes with disabilities may itself favor these erroneous preconceptions. The emergent theme "the opinion of others" expressed the idea that when other athletes (teammates/opponents) discover that a certain athlete is seeing a sport psychologist that may become a weakness for the athlete. Receiving psychological support represents a disadvantage in the view of other athletes. This argument also integrates the group of myths surrounding psychological skills training well described by Burton and Raedake (2008). In fact, many athletes may fear stigmatization or derogation by "others," which can become a barrier to a sport psychology intervention. Stigma can be related to the erroneous idea that those who need to work on psychological skills are weak and have some psychological problem. The psychological problem is associated with the perception of the sport psychologist as a "head-shrinker" who is going to solve a mental health issue (Burton \& Raedake, 2008).

When participants were asked to identify their psychological needs, several athletes mentioned that they did not have any aspect to enhance in their psychological preparation. Some of the reasons pointed to (e.g., satisfaction with self-psychological skills) are in accordance with Leffingwell and colleagues (2001). The authors explained that athletes with great psychological skills believe they do 
not require assistance from sport psychologists. Others may be satisfied with their level of performance and legitimately choose not to use those services, despite being aware of the psychological benefits of such intervention. The fact that one athlete revealed never having thought about his psychological needs must be taken into consideration. This position may express lack of awareness about the possibility of training psychological skills and, consequently, the improvement of psychological preparation.

\section{Conclusions}

Theathletes were unanimous in acknowledging the importance of psychological preparation and revealed receptivity and need for consulting with sport psychologists. However, they also expressed some stigmas associated with sport psychologists' intervention, namely athlete age, perception of psychological skills as innate characteristics, and the opinion of others. The lack of opportunities to receive psychological skills training was also quite clear. A small number of participants recognized the need to improve a specific psychological skill (e.g., concentration and activation) or technique (e.g., imagery and relaxation).

Limitations of the current research have also to be taken into consideration. The small sample studied involved a group of unique characteristics including a focus on only two types of disabilities (physical disability and visual impairment) in one type of sport (individual sport), with a predominance of male athletes. Finally, methodological limitations related to the type of instrument used (i.e., the collected data depended solely on interviews) have to be considered.

\section{Perspectives}

This study provides useful insight into the current state of applied sport psychology in Portuguese disability sport. The results stressed a serious need for psychological intervention. Training in psychological skills is important not only for athletes who admitted having psychological weakness, but also for those who consider themselves to have "strong" minds. Psychological skills training is an effective tool that can enhance athletes' overall psychological function and performance. In addition, it can work as an advantageous process to empower athletes already psychologically gifted, helping them to achieve even better results and to perform consistently. Moreover, the misconceptions about psychological preparation mentioned in the present study show the need to assume an educational and constructive perspective when approaching athletes before a sport psychologist intervention. Overall, the evidence of this research will help practitioners (i.e., applied sport psychologists, coaches, and athletes) to define the most effective ways to conduct psychological skills training programs according to the athletes' attitudes toward this specific topic.

\section{Author affiliations:}

1 Centre of Research, Education, Innovation and Intervention in Sport (CIFI2D), Faculty of Sport, University of Porto, Porto, Portugal; tbastos@fade.up.pt*

2 Research Centre in Physical Activity, Health and Leisure (CIAFEL), Faculty of Sport, University of Porto, Porto, Portugal; rcorredeira@fade.up.pt

3 Faculty of Kinesiology and Rehabilitation Sciences, Research Group for Adapted Physical Activity and Psychomotor Rehabilitation, KU Leuven, Leuven, Belgium; michel.probst@kuleuven.be

1 Centre of Research, Education, Innovation and Intervention in Sport (CIFI2D), Faculty of Sport, University of Porto, Porto, Portugal; afonseca@fade.up.pt

* Correspondence: tbastos@fade.up.pt; Tel.: +351-220-425-211

Author Contributions: Conceptualization, T.B., R.C., A.F.; Methodology, T.B., R.C., M.P., A.F.; Formal Analysis, T.B., R.C., M .P.; W riting-Original Draft Preparation, T.B.; W riting-Review \& Editing, T.B.., R.C., M.P., A.F.

Funding: This research was funded by the Portuguese Foundation for Science and Technology (FCT) $\mathrm{SFRH} / \mathrm{BD} / 48018 / 2008$

Conflicts of Interest: The authors declare no conflict of interest. 


\section{References}

Bawden, M . (2006). Providing sport psychology support for athletes with disabilities. In J. Dosil (Ed.), The sport psychologist's handbook: A guide for sport-specific performance enhancement (pp. 665-683). Chichester, UK: John W iley and Sons, Inc. https://doi.org/10.1002/9780470713174.ch29

Bastos, T., Corredeira, R., Probst, M ., \& Fonseca, A. M . (2014). Elite disability sport coaches' views on sport psychology. International J ournal of Psychological Studies, 6(1) 33-44. https://doi.org/ 10.5539/ijps.v6n1p33

Bastos, T., \& M artin, J. J. (2015). The psychosocial dynamics of sport participation for athletes with intellectual impairments. In E. S. Linton (Ed.), Advances in Sports Research (pp. 1-14). Hauppauge, NY: Nova Science Press

Blumenstein, B., \& Orbach, I. (2015). Psychological preparation for paralympic athletes: A preliminary study. Adapted Physical Activity Quarterly, 32, 241-255. https://doi.org/10.1123/APAQ.2014-0235

Braun, V., Clarke, V., \& W eate, P. (2016). Using thematic analysis in sport and exercise research. In B. Smith $\&$ A. C. Sparks (Eds.), Routledge handbook of qualitative research in sport and exercise (pp. 191-205). N ew York, NY: Routledge.

Bull, S. J. (1991). Personal and situational influences on adherence to mental skills training. Journal of Sport and Exercise Psychology, 13, 121-132. https://doi.org/10.1123/jsep.13.2.121

Burton, D., \& Raedeke, T. D. (2008). Sport psychology for coaches. Champaign, IL: H uman Kinetics.

Campbell, E., \& Jones, G. (2002). Sources of stress experienced by elite male wheelchair basketball players. Adapted Physical Activity Quarterly, 19, 82-99. https://doi.org/10.1123/apaq.19.1.82

Daw, J., \& Burton, D. (1994). Evaluation of a comprehensive psychological skills training program for collegiate tennis players. The Sport Psychologist, 8, 37-57. https://doi.org/10.1123/tsp.8.1.37

de Bressy de Guast, V., Golby, J., Van Wersch, A., \& d'Arripe-Longueville, F. (2013). Psychological skills training of an elite wheelchair water-skiing athlete: A single-case study. Adapted Physical Activity Quarterly, 30, 351-372. https://doi.org/10.1123/apaq.30.4.351

Dieffenbach, K., Statler, T., \& M offet, A. (2010, M ay). Preand post games perception of factors influencing coach and athlete performance at the Beijing Paralympics. Paper presented at the A mazing Leaders Paralympic Conference, Colorado Spring, $\mathrm{CO}$.

Eddy, K. A., \& M ellalieu, S. D. (2003). M ental imagery in athletes with visual impairments. Adapted Physical Activity Quarterly, 20, 347-368. https://doi.org/10.1123/apaq.20.4.347

Gould, D., Flett, M. R., \& Bean, E. (2009). M ental preparation for training and competition. In B. W. Brewer (Ed.), H andbook of sports medicine and science: Sport psychology (pp. 53-63). Chichester, UK: WileyBlackwell Publishing. https://doi.org/10.1002/9781444303650.ch6

H anrahan, S. J. (2007). A thletes with disabilities. In G. Tenenbaum \& R. C. Eklund (Eds.), H andbook of sport psychology (3rd ed., pp. 845-858). N ew Jersey, NJ: John W iley and Sons, Inc. https://doi.org/10.1002/9781118270011.ch38

H anrahan, S. J. (2015). Psychological skills training for athletes with disabilities. Australian Psychologist, 50, 102-105. https://doi.org/10.1111/ap.12083

H anrahan, S. J., Grove, J. R., \& Lockwood, R. J. (1990). Psychological skills training for the blind athlete: A pilot program. A dapted Physical Activity Quarterly, 7, 143-155. https://doi.org/10.1123/apaq.7.2.143

Leffingwell, T. R., Durand-Bush, N., W urzberger, D., \& Cada, P. (2005). Psychological assessment. In J. Taylor $\&$ G. Wilson (Eds.), A pplying sport psychology: Four perspectives (pp. 85-100). Champaign, IL: H uman Kinetics.

Leffingwell, T. R., Rider, S. P., \& W illiams, J. M . (2001). A pplication of the transtheoretical model to psychological skills training. The Sport Psychologist, 15, 168-187. https://doi.org/10.1123/tsp.15.2.168

M artin, J. J. (2005). Sport psychology consulting with athletes with disabilities. Sport and Exercise Psychology Review, 1(2), 32-39.

M artin, J. J. (2010). Psychological skills for athletes with physical disabilities. In S. Hanrahan \& M. Anderson (Eds.), H andbook of applied sport psychology (pp. 432-440). N ew York, NY: Routledge Publishing.

M artin, J. J. (2017). H andbook of disability sport and exercise psychology. N ew Y ork, NY: Oxford University Press. https://doi.org/10.1093/0so/9780190638054.001.0001 
M artin, J. J., M alone, L. A., \& Hilyer, J. C. (2011). Personality and mood in women's Paralympic basketball champions. Journal of Clinical Sport Psychology, 5, 197-210. https://doi.org/10.1123/jcsp.5.3.197

M artin, J. J., \& M alone, L. A. (2013). Elite wheelchair rugby players' mental skills and sport engagement. Journal of Clinical Sport Psychology, 7, 253-263. https://doi.org/10.1123/jcsp.7.4.253

M artin, J. J., \& Wheeler, G. (2011). Psychology. In Y. C. Vanlandewijck \& W . R. Thompson (Eds.), The paralympic athlete: Handbook of sports medicine and science (pp. 116-134). Oxford, UK: W iley-Blackwell. https://doi.org/10.1002/9781444328356.ch7

Page, S., M artin, S. B., \& W ayda, V. K. (2001). Attitudes toward seeking sport psychology consultation of wheelchair basketball athletes. Adapted Physical Activity Quarterly, 18, 183-192. https://doi.org/10.13140/2.1.3418.6889

Samulski, D. M., N oce, F., \& Costa, V. T. (2011). Mental preparation. In Y. C. Vanlandewijck \& W . R Thompson (Eds.), The paralympic athlete: $\mathrm{H}$ andbook of sports medicine and science (pp. 198-213). Oxford, UK: Wiley-Blackwell. https://doi.org/10.1002/9781444328356.ch11

Schinke, R. J., \& Hanrahan, S. J. (2009). Cultural sport psychology. Champaign, IL: H uman Kinetics.

Shearer, D., M ellalieu, S., Shearer, C., \& Roderique-D avies, G. (2009). The effects of a video-aided imagery intervention upon collective efficacy in an international Paralympic wheelchair basketball team. Journal of Imagery Research in Sport and Physical Activity, 4(1), 1-25. https://doi.org/10.2202/1932-0191.1039

Smith, B. (2018). Generalization in qualitative research: M isunderstanding, opportunities and recommendations for the sport and exercise sciences. Qualitative Research in Sport, Exercise and $\mathrm{H}$ ealth, 10, 137-149. https://doi.org/10.1080/2159676X.2017.1393221

Smith, B., \& M cGannon, K. R. (2018). Developing rigor in qualitative research: Problems and opportunities within sport and exercise psychology. International Review of Sport and Exercise Psychology, 1(11), 101121. https://doi.org/10.1080/1750984X.2017.1317357

Smith, B., \& Sparks, A. C. (2016). Interviews: Qualitative interviewing in the sport and exercise sciences. In B. Smith \& A. C. Sparks (Eds.), Routledge handbook of qualitative research in sport and exercise (pp. 103123). N ew York, NY: Routledge.

Smith, J. A. (2004). Reflecting on the development of interpretative phenomenological analysis and its contribution to qualitative research in psychology. Qualitative Research in Psychology, 1, 39-54.

W einberg, R., \& Gould, D. (2011). Foundations of sport and exercise psychology (5th ed.). Champaign, IL: H uman Kinetics.

Wheeler, G. D., Steadward, R. D., Legg, D ., H utzler, Y., Campbell, J., \& Johnson, A . (1999). Personal investment in disability sport careers: An international study. Adapted Physical Activity Quarterly, 16, 219-137. https://doi.org/10.1123/apaq.16.3.219

Williams, T., \& Taylor, D. (1994). Socialization, subculture, and wheelchair sport: The influence of peers in wheelchair racing. Adapted Physical Activity Quarterly, 11, 416-428.

https://doi.org/10.1123/apaq.11.4.416

(c) 2020 by the authors. Submitted for possible open access publication under the terms and conditions of the Creative Commons Attribution (CC BY) license (http://creativecommons.org/licenses/by/4.0/). 